\title{
Substituent Effects on the $\sigma \cdots \pi$ Interactions Between Au6 Cluster and Substituted Benzene
}

Qiang Zhao ( $\nabla$ qzhaochem@126.com )

School of Materials and Chemical Engineering, Zibo Vocational Institute

\section{Research Article}

Keywords: substituent effects, $\sigma \cdots \pi$ interaction, Au6 cluster, electron-donating, electron-withdrawing, electrostatic interaction, dispersion

Posted Date: July 27th, 2021

DOI: https://doi.org/10.21203/rs.3.rs-719647/v1

License: (c) (i) This work is licensed under a Creative Commons Attribution 4.0 International License. Read Full License 
Substituent effects on the $\sigma \cdots \pi$ interactions between $\mathrm{Au}_{6}$ cluster and substituted benzene

Qiang Zhao ${ }^{1, *}$

( ${ }^{1}$ School of Materials and Chemical Engineering, Zibo Vocational

Institute, Zibo 255314, Shandong Province, P. R. China)

Corresponding author: Qiang Zhao

E-mail: qzhaochem@126.com

Tel: +86-13864428619 


\begin{abstract}
The $\sigma \cdots \pi$ interactions in the $\mathrm{Au}_{6} \cdots \mathrm{PhX}\left(\mathrm{X}=\mathrm{H}, \mathrm{CH}_{3}, \mathrm{OH}, \mathrm{OCH}_{3}, \mathrm{NH}_{2}, \mathrm{~F}, \mathrm{Cl}, \mathrm{Br}, \mathrm{CN}\right.$, $\mathrm{NO}_{2}$ ) complexes are studied using quantum chemical methods. The present study focuses on the different effects of electron-donating and -withdrawing substituent. The structure and binding strength of the complexes are examined. The interactions between $\mathrm{Au}_{6}$ cluster and various substituted benzene become strengthened relative to the $\mathrm{Au}_{6} \cdots$ benzene complex. The interaction region indicator analysis was performed, and the interaction region and interaction between the substituent and $\mathrm{Au}_{6}$ cluster are discussed. It is found that the substituent effects on the $\sigma \cdots \pi$ interactions between $\mathrm{Au}_{6}$ cluster and substituted benzene are different from $\pi \cdots \pi$ interactions of benzene dimer. Energy decomposition analysis was carried out to study the nature of $\sigma \cdots \pi$ interactions, and the substituent effects are mainly reflected on the electrostatic interaction and dispersion.
\end{abstract}

\title{
Key words
}

substituent effects; $\sigma \cdots \pi$ interaction; $\mathrm{Au}_{6} \quad$ cluster; electron-donating; electron-withdrawing; electrostatic interaction; dispersion 


\section{Declarations}

\section{Funding}

No funding was received to assist with the preparation of this manuscript.

\section{Conflicts of interest}

The author declares that I have no conflict(s) of interest.

\section{Availability of data and material}

Confirmed.

\section{Code availability}

Confirmed.

\section{Authors' contributions}

Qiang Zhao has done all of the works in the investigation, calculation, and writing - review and editing.

\section{Ethics approval}

Not applicable.

\section{Consent to participate}

The author consents to participation.

\section{Consent for publication}

The participant consents to publication. 


\section{Introduction}

Stacking interactions between aromatic rings, especially $\pi \cdots \pi$ interactions [1-3], play important role in the fields of catalyst design [4], supramolecular chemistry [5], crystal engineering [6], protein-ligand recognition [7-8], and DNA stabilization [9]. The stacking interaction between benzene $(\mathrm{Bz})$ dimer is one of the most widely studied interactions in recent years [10-13]. The parallel displaced (PD) and T-shaped configurations are approximately equal in stability, which are more stronger than the parallel stacked (PS) geometry [14]. For the PD configuration, the stacking interactions come from two factors. First is the $\pi \cdots \pi$ interaction between the $\pi$-cloud of benzene dimer, which is electrostatically repulsive owing to the negative molecular electrostatic potential (MEP). Second is the interaction between the positively charged hydrogen atoms of one benzene and the $\pi$-cloud of the other ring. Interestingly, the $\sigma$-electron could participate stacking interactions. For example, the $\sigma \cdots \sigma$ interaction strength between cyclohexane dimer is $-3.09 \mathrm{kcal} \cdot \mathrm{mol}^{-1}$, which is stronger than that of benzene dimer [15]. The $\sigma \cdots \pi$ interaction between cyclohexane and benzene $\left(-2.91 \mathrm{kcal} \cdot \mathrm{mol}^{-1}\right)$ is more stabilized than that of benzene dimer with PS geometry $\left(-1.63 \mathrm{kcal} \cdot \mathrm{mol}^{-1}\right)[16]$.

Stacking interaction can be tuned through substituent effects, and there are a great number of studies about its physical mechanism in the past two decades [17-26]. Two popular hypothesis were proposed to understand the nature of substituent effects. The viewpoint of Hunter and Sanders (HS) [17] was based on the polarization of the $\pi$-system by the substituent. Electron-withdrawing substituent can enhance the PS stacking interactions by decreasing the $\pi$-electron density of the ring, whereas introduction of electron-donating substituent should hinder the interactions through the opposite mechanism [27-28]. Wheeler and Houk (WH) proposed that the direct interaction between the substituent and the other aromatic ring determines the substituent effects on the interaction energy [16, 20, 23, 25]. Moreover, they found that the substituent effects in the PD and PS geometries are essentially identical [23], which is in conflict with the HS view. Parrish and Sherrill [26] pointed out that both HS and WH pictures contribute to the substituent effects on stacking interactions, but 
the $\mathrm{WH}$ picture is usually dominant.

Recently, the non-covalent interactions in which coinage metal $(\mathrm{Cu}, \mathrm{Ag}$, and $\mathrm{Au})$ nanoclusters involved have been received great attentions [27-36]. Regium bond [29] was introduced to represent the interaction between coinage metal nanoparticles and an electron rich moiety. MEP analysis of coinage metal clusters showed that there exists depleted electron density regions with positive MEPs [30] (also be called as $\sigma$-hole [37]) in the low-coordinated metal sites, and negative MEPs are located at bridge and hollow sites. It is well-known that benzene can absorb on coinage metals with weakly interactions [38-42]. The research was mainly focused on the (111) coinage metal surface, and this adsorption is a weak physisorption, which is dominated by van der Waals (vdW) interactions.

Substituent effects also exist in the interaction when aromatic ring adsorbed on the metal surface. For example, Peköz et al. [43] investigated the adsorption of polyhalogenated benzene on the $\operatorname{Pt}(111)$ surface, and they found that the relative stability of chemisorption and physisorption can be tuned by the type or the number of halogen atoms. Miller and co-workers [44] studied the adsorption of benzene functionalized with one or two substituents on $\operatorname{Ag}(111)$ surface, which indicates that strong electron-donating or -withdrawing substituent possessed a distinct site preference.

Given the weak absorption of benzene on the coinage metal surface, the interaction between gold cluster and benzene could be classified into $\sigma \cdots \pi$ interaction. Moreover, the HS and WH pictures could be applied to describe the substituent effects on the interaction. In this paper, the stacking interaction in the $\mathrm{Au}_{6} \cdots \mathrm{Bz}$ complex was investigated using quantum chemical methods. $\mathrm{Au}_{6}$ cluster, which has been proved to have planar geometry [45-46], has the same number of atom in the ring as benzene. Figure 1 shows the MEP mapped vdW surfaces of $\mathrm{Au}_{6}$ cluster and benzene, and it is seen that the MEP distribution of these two moieties are very similar. Nine mono-substituted benzene derivatives $\left(\mathrm{Ph}-\mathrm{CH}_{3}, \mathrm{Ph}-\mathrm{OH}, \mathrm{Ph}-\mathrm{NH}_{2}, \mathrm{Ph}-\mathrm{OCH}_{3}, \mathrm{Ph}-\mathrm{F}\right.$, $\mathrm{Ph}-\mathrm{Cl}, \mathrm{Ph}-\mathrm{Br}, \mathrm{Ph}-\mathrm{CN}$, and $\mathrm{Ph}-\mathrm{NO}_{2}$ ) are chosen to interact with $\mathrm{Au}_{6}$ cluster to study the substituent effects of the stacking interactions. The geometry and binding strength of 
the complexes are studied. With the help of interaction region indicator (IRI) analysis, the interaction regions between the $\mathrm{Au}_{6}$ cluster and mono-substituted benzene are displayed. Energy decomposition analysis was carried out to study the nature of the substituent effects using the symmetry adapted perturbation theory (SAPT).
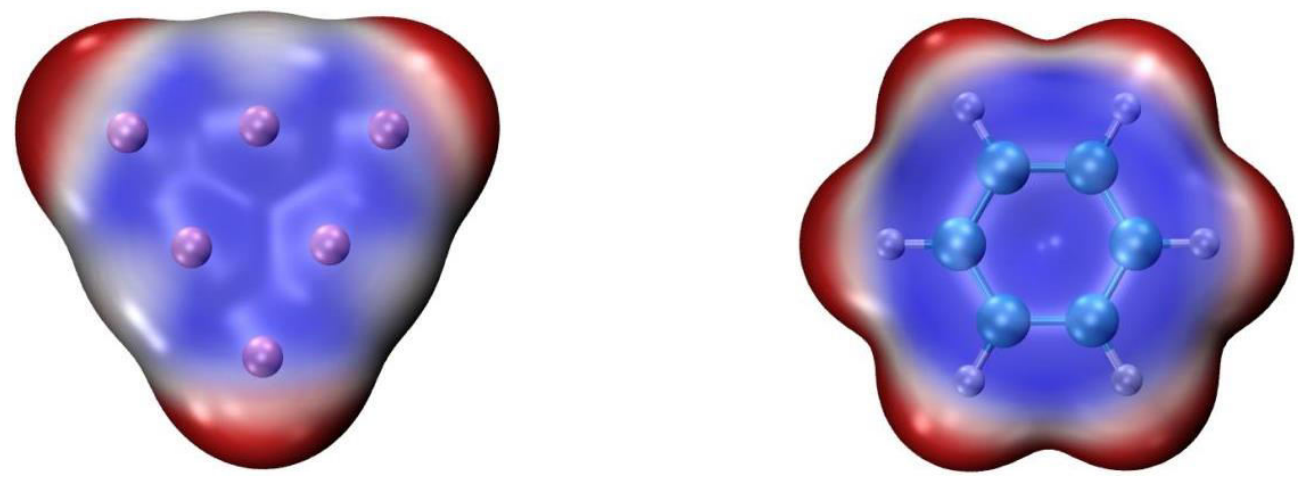

-0.01 a.u. +0.01 a.u.

Figure 1 MEP mapped vdW surface (isosurface of $\rho=0.001$ a.u.) of $\mathrm{Au}_{6}$ cluster and benzene.

\section{Theoretical methods}

Geometry optimizations were implemented using PBE0 exchange-correlation functional [47-48] in conjunction with def2-TZVP [49] basis set. Previous studies have proved that PBE0 is able to describe the non-covalent interactions including transition metals [50-52]. Frequency analyses were carried out at the same level and all geometries are characterized to minima on the potential energy surface. Grimme's DFT-D3(BJ) empirical dispersion correction [53] was used in the geometry optimizations. The above calculations were performed using Gaussian 09 software (revision D.01) [54].

In order to obtain accurate binding energy of the stacking interaction, single point calculations were performed at the PWRB95-D3(BJ)/def2-QZVPP level. The combination between double hybrid functional PWRB95 [55] and larger basis set def2-QZVPP [49] can give improved binding energy for weakly interaction systems. Binding energies were calculated as $E_{b}=E_{c}-E_{A u 6}-E_{P h X}$ where $E_{\mathrm{c}}$ corresponds to 
the energy of the complex and $E_{\mathrm{Au} 6}$ and $E_{\mathrm{PhX}}$ refer to the energies of $\mathrm{Au}_{6}$ and $\mathrm{Bz}$ or substituted benzene in the complex, respectively. The Counterpoise correction was adapted using Boys and Bernardi's method [56] to evaluate the basis set superposition error (BSSE). The ORCA 4.2.1 program [57] was employed for this part of calculation. The RI and RIJCOSX [56] technique were used to accelerate the calculation. SAPT analysis [59] using the scaled SAPT0 method with def2-SVP basis set was carried out with the help of PSI4 1.3.2 code [60]. The total interaction energy of this level is in consistent with the result of PBE0/def2-TZVP calculation.

The MEP mapped vdW surface on the 0.001 a.u. contours of the electronic density was generated at the PBE0-D3(BJ)/def2-TZVP level. To intuitively show the stacking interaction in real space, IRI method [61] was applied. The above analysis were performed with the Multiwfn code [62]. Molecular graphs of MEP and IRI maps are rendered by means of Visual Molecular Dynamics (VMD) software [63]. Since the main focus is stacking interaction, the other types of interaction are not included in this paper.

\section{Results and discussion}

\section{Geometries and binding energies}

The optimized structures of the $\mathrm{Au}_{6} \cdots \mathrm{Bz}$ complex and benzene dimer are displayed in Figure 2. Three geometrical parameters $\left(R, \theta_{1}\right.$, and $\left.\theta_{2}\right)$ are defined. $R$ denotes the distance between the molecular plane of $\mathrm{Au}_{6}$ cluster and benzene, and $\theta_{1}$ and $\theta_{2}$ is misalignment angle and the included angle of the two planes, respectively. The geometrical parameter and binding energy are collected in Table 1. One can see that the structure of the $\mathrm{Au}_{6} \cdots \mathrm{Bz}$ complex is similar to that of $\mathrm{Bz} \cdots \mathrm{Bz}$, for which the PD geometry is the most stable configuration. The value of $R$ in the $\mathrm{Au}_{6} \cdots \mathrm{Bz}$ complex is $3.783 \AA$, which is smaller than that of benzene dimer. This indicates that the $\mathrm{Au}_{6}$ and $\mathrm{Bz}$ molecular plane get closer from the direction perpendicular to the ring in the former complex. Misalignment angle $\theta_{l}$ reflects the overlap degree along the ring. It is seen that this value in the $\mathrm{Au}_{6} \cdots \mathrm{Bz}$ complex is slightly larger than that of benzene dimer, which indicates that the molecular plane overlap of $\sigma \cdots \pi$ interaction is a little 
smaller than $\pi \cdots \pi$ interaction. Moreover, the two aromatic rings in the benzene dimer is almost flat, and the plane of $\mathrm{Au}_{6}$ cluster presents small deviation with the included angle of $3.29^{\circ}$. The binding energy of benzene dimer at the PWRB95-D3(BJ)/def2-QZVPP level is $-2.93 \mathrm{kcal} \cdot \mathrm{mol}^{-1}$, which is in accord with the S66 database [64], where interaction strength of $\pi \cdots \pi$ interaction is $-2.82 \mathrm{kcal} \cdot \mathrm{mol}^{-1}$. This demonstrates that the result in this study should be reliable. The binding energy of the $\mathrm{Au}_{6} \cdots \mathrm{Bz}$ complex is $-10.57 \mathrm{kcal} \cdot \mathrm{mol}^{-1}$, which is even more than three times than that of PD benzene dimer. This indicates that the $\sigma \cdots \pi$ interaction in the $\mathrm{Au}_{6} \cdots \mathrm{Bz}$ complex is far more strengthened than that of $\pi \cdots \pi$ interaction of benzene dimer. It is interesting to note that the experimental adsorption energy of benzene on $\mathrm{Au}(111)$ is $0.64 \mathrm{eV}$ (about $14.78 \mathrm{kcal} \cdot \mathrm{mol}^{-1}$ ) [65], which is comparable to the binding energy of $\mathrm{Au}_{6} \cdots \mathrm{Bz}$ complex.

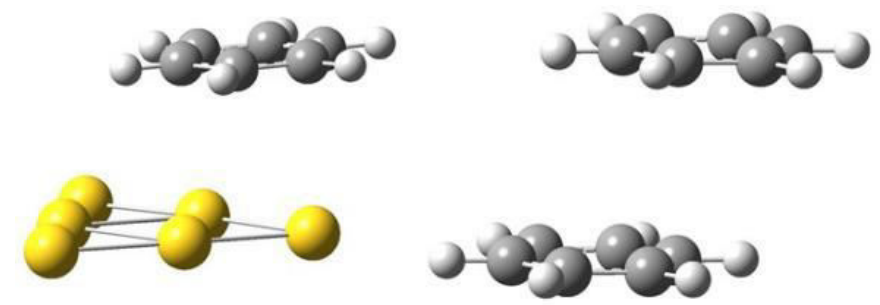

side view
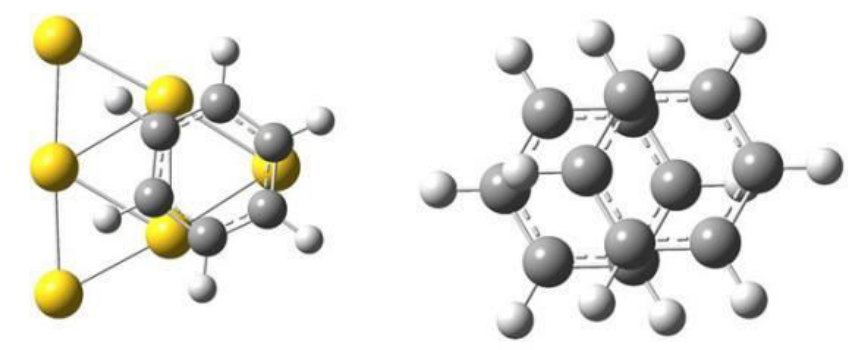

top view

Figure 2 Optimized structures of the $\mathrm{Au}_{6} \cdots \mathrm{Bz}$ complex and benzene dimer.

Table 1 Geometrical parameters $\left(R\right.$ in $\AA$ and $\theta$ in $\left.{ }^{\circ}\right)$ and binding energies $\left(E_{\mathrm{b}}\right.$ in $\mathrm{kcal} \cdot \mathrm{mol}^{-1}$, at the PWRB95-D3(BJ)/def2-QZVPP level) of the $\mathrm{Au}_{6} \cdots \mathrm{Bz}$ complex and benzene dimer.

\begin{tabular}{|l|l|l|l|l|}
\hline complex & $R$ & $\theta_{1}$ & $\theta_{2}$ & $E_{b}$ \\
\hline $\mathrm{Au}_{6} \cdots \mathrm{Bz}$ & 3.783 & 30.32 & 3.29 & -10.57 \\
\hline $\mathrm{Bz} \cdots \mathrm{Bz}$ & 3.904 & 26.60 & 0.158 & -2.93 \\
\hline
\end{tabular}


To investigate the substituent effects of the stacking interaction between $\mathrm{Au}_{6}$ cluster and benzene, the $\mathrm{Au}_{6} \cdots \mathrm{PhX}\left(\mathrm{X}=-\mathrm{CH}_{3},-\mathrm{OH},-\mathrm{NH}_{2},-\mathrm{OCH}_{3},-\mathrm{F},-\mathrm{Cl},-\mathrm{Br},-\mathrm{CN},-\mathrm{NO}_{2}\right)$ complexes were optimized. Careful configuration search was performed to sample all possible stable stacked structures of the complexes. The result is there is little influence on the binding energy when the position of the substituent changed. That is to say, rotation of aromatic ring along the axis which perpendicular to the ring has negligible effect on the $\sigma \cdots \pi$ interactions between $\mathrm{Au}_{6}$ cluster and substituted benzene. The optimized structures of the $\mathrm{Au}_{6} \cdots \mathrm{PhX}$ complexes are displayed in Figure 3. One can see that there has been no apparent change on the structures of $\mathrm{Au}_{6} \cdots \mathrm{PhCH}_{3}$, $\mathrm{Au}_{6} \cdots \mathrm{PhOH}, \mathrm{Au}_{6} \cdots \mathrm{PhNH}_{2}, \mathrm{Au}_{6} \cdots \mathrm{PhOCH}_{3}, \mathrm{Au}_{6} \cdots \mathrm{PhF}$ compared to the $\mathrm{Au}_{6} \cdots \mathrm{Bz}$ complex. In the $\mathrm{Au}_{6} \cdots \mathrm{PhCl}, \mathrm{Au}_{6} \cdots \mathrm{PhBr}, \mathrm{Au} \cdots \mathrm{PhCN}$, and $\mathrm{Au} \cdots \mathrm{PhNO}_{2}$ complexes, the overlap between $\mathrm{Au}_{6}$ cluster and substituted benzene becomes more prominent, which induced a trend of change from PD to PS configuration. Table 2 summarizes the geometrical parameter and binding energy of the $\mathrm{Au}_{6} \cdots \mathrm{PhX}$ complexes. It is seen that $\theta_{2}$ values were not changed so much, which indicates that substituent did not alter the orientation of the stacking interactions. In the $\mathrm{Au}_{6} \cdots \mathrm{PhCH}_{3}$ complex, the values of $R$ and $\theta_{1}$ is almost the same as those in $\mathrm{Au}_{6} \cdots \mathrm{Bz}$. For the electron-donating substituent $-\mathrm{NH}_{2}$ and $-\mathrm{OCH}_{3}, R$ and $\theta_{1}$ increased. It makes sense that electron-donating substituent increased the $\pi$-cloud of the ring, and $\mathrm{Au}_{6}$ cluster and substituted benzene become more separated. For the electron-withdrawing substituent $(-\mathrm{F},-\mathrm{Cl},-\mathrm{Br},-\mathrm{CN}$, $\left.-\mathrm{NO}_{2}\right), R$ and $\theta_{1}$ decreased in the $\mathrm{Au}_{6} \cdots \mathrm{PhX}$ complexes, which can attributed to the less repulsion effect between the $\sigma$ electrons and $\pi$-cloud. The geometrical parameter of $\mathrm{Au}_{6} \cdots \mathrm{PhOH}$ complex is interesting because the values of $R$ and $\theta_{1}$ decreased, which is contrary to the electron-donating character of $-\mathrm{OH}$. This indicates that $-\mathrm{OH}$ present some electron-withdrawing character. 


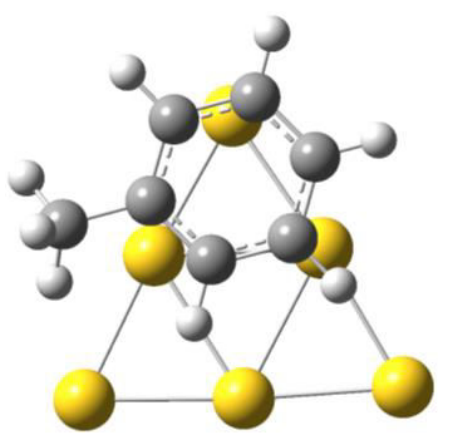

$\mathrm{Au}_{6} \cdots \mathrm{PhCH}_{3}$

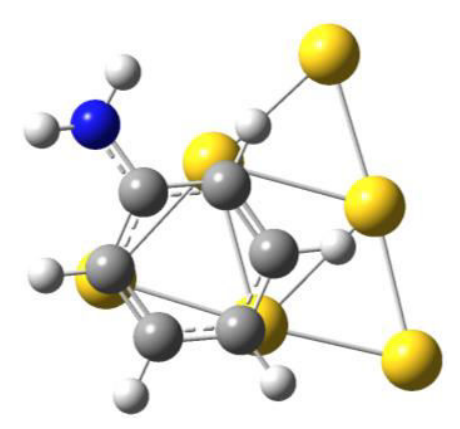

$\mathrm{Au}_{6} \cdots \mathrm{PhNH}_{2}$

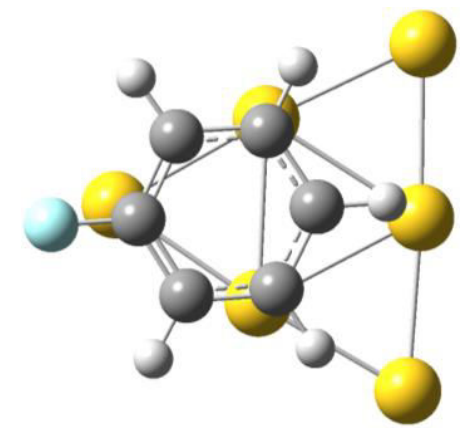

$\mathrm{Au}_{6} \cdots \mathrm{PhF}$

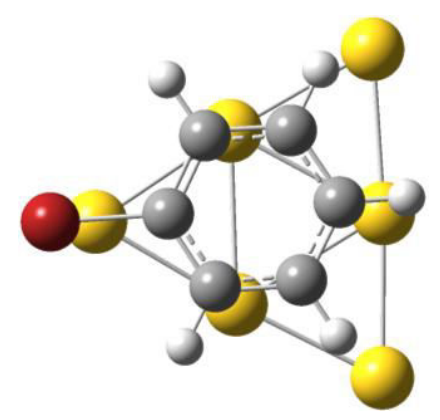

$\mathrm{Au}_{6} \cdots \mathrm{PhBr}$

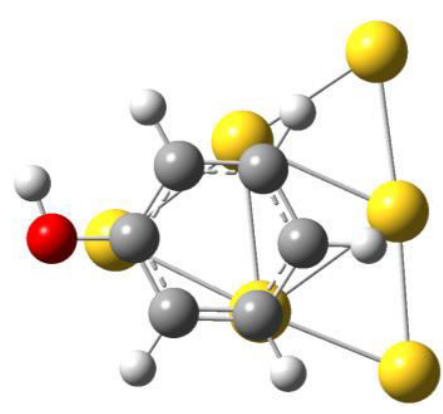

$\mathrm{Au}_{6} \cdots \mathrm{PhOH}$

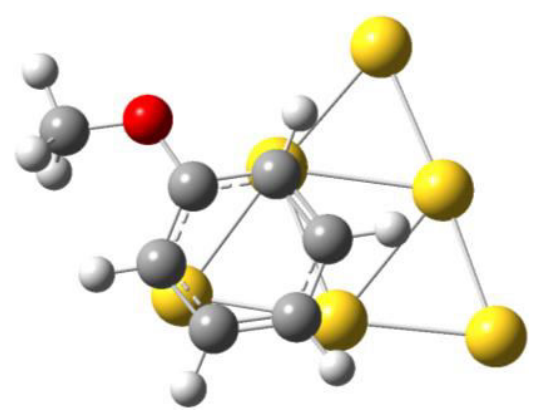

$\mathrm{Au}_{6} \cdots \mathrm{PhOCH}_{3}$

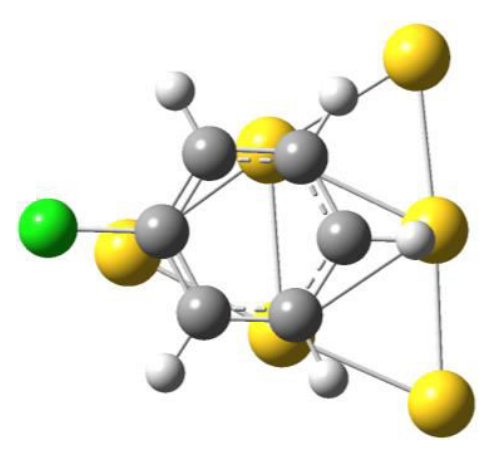

$\mathrm{Au}_{6} \cdots \mathrm{PhCl}$

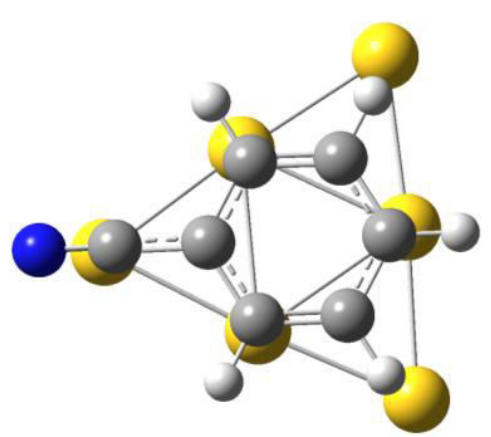

$\mathrm{Au}_{6} \cdots \mathrm{PhCN}$ 


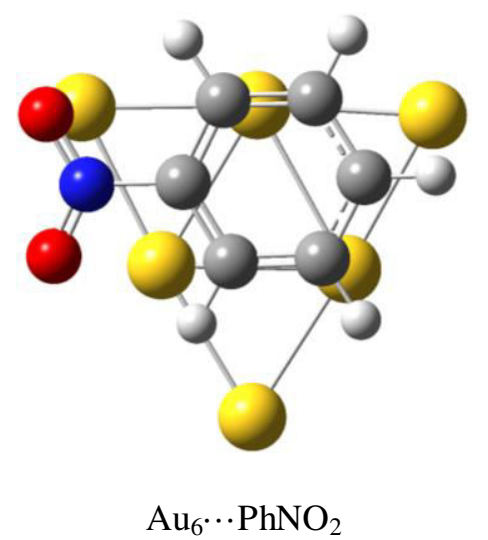

Figure 3 The structures (top view) of the $\mathrm{Au}_{6} \cdots P h X$ complexes optimized at the PBE0/def2-TZVP level.

The binding energy of the $\sigma^{\cdots} \pi$ interaction spans a range from -10.51 to $-12.83 \mathrm{kcal} \cdot \mathrm{mol}^{-1}$. The weakest complex is $\mathrm{Au}_{6} \cdots \mathrm{PhF}$, which is almost identical with $\mathrm{Au}_{6} \cdots \mathrm{Bz}$ in strength $\left(-10.51\right.$ v.s. $\left.-10.57 \mathrm{kcal} \cdot \mathrm{mol}^{-1}\right)$. This is similar to the study of absorption of $\mathrm{PhF}$ on $\operatorname{Ag}(111)$ [44], in which the binding strength is weaker than that of benzene. The binding energy of the $\sigma \cdots \pi$ interaction is different from the results of PD and PS benzene dimer. Theoretical study [18] has suggest that the introduction of any substituent should increase the strength of $\pi$-stacking interaction of benzene dimer. Moreover, the electron-withdrawing substituent makes the $\pi$-stacking interaction more stronger than the electron-donating substituent. This can be easily explained by the $\pi$-polarization model because electron-withdrawing substituent decreases the repulsion between $\pi$-cloud and increases the acidity of hydrogen atoms. In the $\mathrm{Au}_{6} \cdots \mathrm{PhX}$ complexes, the $\sigma \cdots \pi$ interactions have been strengthened through the substituent effects except for the $\mathrm{Au}_{6} \cdots \mathrm{PhF}$ complex. Overall, the influence of electron-withdrawing substituent is more pronounced than the electron-donating substituent. There is a correlation between interaction energy and the Hammett sigma meta constants $\left(\sigma_{\mathrm{m}}\right)$ for the PS dimer of substituted benzene, but there is not distinct relationship between binding energy and $\sigma_{\mathrm{m}}$ in the $\mathrm{Au}_{6} \cdots \mathrm{PhX}$ complexes. For example, the binding energies of the $\mathrm{Au}_{6} \cdots \mathrm{PhCH}_{3}$ and $\mathrm{Au}_{6} \cdots \mathrm{PhCN}$ complexes are -12.18 and $-11.95 \mathrm{kcal} \cdot \mathrm{mol}^{-1}$, respectively. This could not reflect the difference between electron-donating substituent $-\mathrm{CH}_{3}$ and electron-withdrawing substituent - $\mathrm{CN}$. From 
the above discussion, it is seen that the $\sigma \cdots \pi$ interactions between $\mathrm{Au}_{6}$ cluster and substituent benzene can not fully understood in terms of the character of the substituent. There exists correlation between dispersion energy and the $\pi$ components of the polarizability of substituted benzene [18]. From this, the polarizability $\left(P_{\mathrm{ZZ}}\right)$ in the direction perpendicular to the molecular plane of substituted benzene was calculated at the PBE0-D3(BJ)/def2-TZVP level. The $P_{\mathrm{ZZ}}$ values of $\mathrm{Au}_{6}$ cluster and benzene are 118.86 and 38.37a.u., respectively, which can account for the strong $\sigma \cdots \pi$ interaction in the $\mathrm{Au}_{6} \cdots \mathrm{BZ}$ complex. It is also found that the $P_{\mathrm{ZZ}}$ values of $\mathrm{PhF}$ and $\mathrm{PhOH}$ are relative small compared to other substituted benzene, which is in accord with the binding energy of the corresponding complexes. Figure 4 displays the scatter diagram between binding energy and the value of $P_{\mathrm{ZZ}}$. One can see that except for the $-\mathrm{OCH}_{3}$ and $-\mathrm{NO}_{2}$ substituent, $E_{\mathrm{b}}$ presents a good correlation with $\mathrm{P}_{\mathrm{ZZ}}$. $\mathrm{PhOCH}_{3}$ has the largest $P_{\mathrm{ZZ}}$ value (51.02a.u.), which is not consistent with the medium binding energy $\left(-12.10 \mathrm{kcal} \cdot \mathrm{mol}^{-1}\right)$. The $\mathrm{P}_{\mathrm{ZZ}}$ value of $\mathrm{PhNO}_{2}$ is 43.09 a.u., but the $\sigma \cdots \pi$ interaction in the $\mathrm{Au}_{6} \cdots \mathrm{PhNO}_{2}$ is very strong $\left(-12.82 \mathrm{kcal} \cdot \mathrm{mol}^{-1}\right)$. This contradiction can be understood by the geometries of the corresponding complexes. It is seen from Figure 2 that the $\mathrm{Au}_{6} \cdots \mathrm{PhOCH}_{3}$ complex has a PD configuration, but the structure of the $\mathrm{Au}_{6} \cdots \mathrm{PhNO}_{2}$ complex is almost a PS geometry. It is obvious that the $-\mathrm{NO}_{2}$ substituent has a direct interaction with $\mathrm{Au}_{6}$ cluster, but for the $\mathrm{Au}_{6} \cdots \mathrm{PhOCH}_{3}$ complex, there is no direct interaction between the $-\mathrm{OCH}_{3}$ substituent and $\mathrm{Au}_{6}$ cluster.

Table 2 Geometrical parameters $\left(R\right.$ in $\AA$ and $\theta$ in $\left.{ }^{\circ}\right)$ and binding energies $\left(E_{\mathrm{b}}\right.$ in $\mathrm{kcal}^{\circ} \mathrm{mol}^{-1}$, at the PWRB95-D3(BJ)/def2-QZVPP level) of the $\mathrm{Au}_{6} \cdots \mathrm{PhX}\left(\mathrm{X}=\mathrm{CH}_{3}, \mathrm{OH}, \mathrm{NH}_{2}, \mathrm{OCH}_{3}, \mathrm{~F}, \mathrm{Cl}\right.$, $\mathrm{Br}, \mathrm{CN}, \mathrm{NO}_{2}$ ) complexes

\begin{tabular}{|l|l|l|l|l|}
\hline complex & $R$ & $\theta_{1}$ & $\theta_{2}$ & $E_{b}$ \\
\hline $\mathrm{Au}_{6} \cdots \mathrm{PhCH}_{3}$ & 3.781 & 30.96 & 4.09 & -12.18 \\
\hline $\mathrm{Au}_{6} \cdots \mathrm{PhOH}$ & 3.656 & 24.88 & 4.05 & -10.97 \\
\hline $\mathrm{Au}_{6} \cdots \mathrm{PhNH}_{2}$ & 3.854 & 32.41 & 4.94 & -11.83 \\
\hline $\mathrm{Au}_{6} \cdots \mathrm{PhOCH}_{3}$ & 3.835 & 34.27 & 1.54 & -12.10 \\
\hline $\mathrm{Au}_{6} \cdots \mathrm{PhF}$ & 3.700 & 25.03 & 5.44 & -10.51 \\
\hline
\end{tabular}




\begin{tabular}{|l|l|l|l|l|}
\hline $\mathrm{Au}_{6} \cdots \mathrm{PhCl}$ & 3.557 & 18.46 & 0.39 & -11.80 \\
\hline $\mathrm{Au}_{6} \cdots \mathrm{PhBr}$ & 3.536 & 17.51 & 4.78 & -12.83 \\
\hline $\mathrm{Au}_{6} \cdots \mathrm{PhCN}$ & 3.541 & 13.74 & 4.65 & -11.95 \\
\hline $\mathrm{Au}_{6} \cdots \mathrm{PhNO}_{2}$ & 3.520 & 10.38 & 6.52 & -12.82 \\
\hline
\end{tabular}

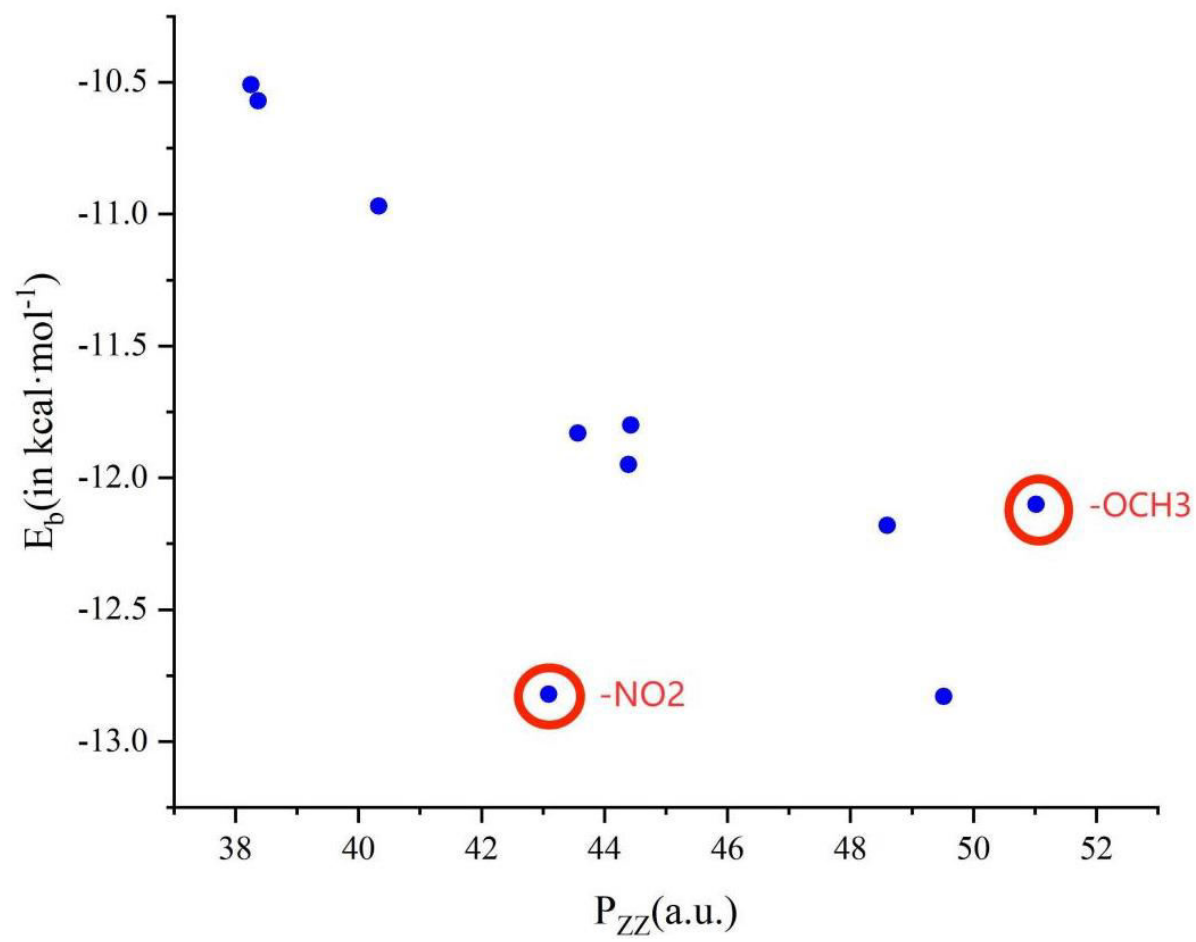

Figure 4 Plot of the binding energy $E_{\mathrm{b}}$ (in $\mathrm{kcal} \cdot \mathrm{mol}^{-1}$, at the PWRB95-D3(BJ)/def2-QZVPP level) v.s. the polarizabilities $P_{\mathrm{ZZ}}$ in the direction perpendicular to the molecular plane in the substituted benzene (in a.u.,at the PBE0-D3(BJ)/def2-TZVP level).

\section{IRI analysis}

To visually exhibit the region of $\sigma \cdots \pi$ interactions in the $\mathrm{Au}_{6} \cdots \mathrm{BZ}$ and $\mathrm{Au}_{6} \cdots \mathrm{PhX}$ complexes, IRI analysis was performed using the PBE0-D3(BJ)/def2-TZVP wave functions. IRI is a a new real space function, which is a slight modification on reduced density gradient (RDG) [61]. IRI is defined as $\operatorname{IRI}(r)=\frac{|\nabla \rho(r)|}{[\rho(r)]^{a}}$, where $\rho$ is electron density and $r$ is coordinate vector. The parameter $a$ is an adjustable parameter, and $a=1.1$ is adopted for standard definition of IRI. In this method, isosurfaces of IRI is employed to exhibit chemical bonding and non-covalent interaction regions. By mapping the $\operatorname{sign}\left(\lambda_{2}\right) \rho$ function onto IRI isosurfaces with different colors, the nature 
of the interactions can be vividly displayed.

Figure 5 shows the IRI isosurface maps of the $\mathrm{Au}_{6} \cdots \mathrm{Bz}$ and $\mathrm{Au}_{6} \cdots \mathrm{PhX}$ complexes, and the map of PD benzene dimer is also collected. It is seen that there are green isosurface in the $\pi$-stacking regions in the benzene dimer, which indicates that the main driving force of the $\pi \cdots \pi$ interaction is $\mathrm{vdW}$ interaction. For the $\mathrm{Au}_{6} \cdots \mathrm{Bz}$ complex, the color of isosurface darkened and the area of the interaction region enlarged. This suggests that the $\sigma \cdots \pi$ interaction is stronger than the $\pi \cdots \pi$ interaction, which is consistent with the result of binding energy. In the $\mathrm{Au}_{6} \cdots \mathrm{PhX}$ complexes, the isosurface shows great variations by different substitute. It is seen that there is not distinct interaction region between $-\mathrm{F}$ and $\mathrm{Au}_{6}$ cluster in the $\mathrm{Au}_{6} \cdots \mathrm{PhF}$ complex and the isosurface is similar to that of $\mathrm{Au}_{6} \cdots \mathrm{Bz}$ complex. This can explain why the strength of $\sigma \cdots \pi$ interaction in these two complexes are almost identical. For the other electron-withdrawing substitute $-\mathrm{Cl},-\mathrm{Br},-\mathrm{CN}$, and $-\mathrm{NO}_{2}$, the IRI isosurface in the corresponding complexes presents similar characteristics. The shape of the isosurface changed from flat in the $\mathrm{Au}_{6} \cdots \mathrm{Bz}$ complex to triangular with larger area in the $\mathrm{Au}_{6} \cdots \mathrm{PhX}$ complexes, and the color of the isosurface become lighter. Meanwhile, there exists obvious interaction between the substituent and $\mathrm{Au}_{6}$ cluster. In particular, this interaction is extremely strong in the $\mathrm{Au}_{6} \cdots \mathrm{PhBr}$ complex, which is responsible for the most negative binding energy of $-12.83 \mathrm{kcal} \cdot \mathrm{mol}^{-1}$. For the electron-donating substitute $-\mathrm{CH}_{3},-\mathrm{OH},-\mathrm{NH}_{2}$, and $-\mathrm{OCH}_{3}$, the color of the isosurface becomes more red, which indicates that the $\mathrm{vdW}$ interactions are strengthened. The areas of the interaction region are not much changed, and there exists only weak interaction between the the substituent and $\mathrm{Au}_{6}$ cluster.

The above analysis reveals that the $\sigma \cdots \pi$ interactions in the $\mathrm{Au}_{6} \cdots \mathrm{PhX}$ complexes should be considered from two aspects. First, the electron-donating substituent made the vdW interaction strengthened. There was little change for the interaction region due to the increasing $\pi$ electron density of the aromatic ring and the interaction between the substituent and $\mathrm{Au}_{6}$ cluster is very weak. Second, the interaction region becomes broader in the complexes with electron-withdrawing substituted benzene, which accounts for the decreasing repulsion between $\sigma$ and $\pi$ electron density. The 
interaction between the substituent and $\mathrm{Au}_{6}$ cluster is very strong except for the $\mathrm{Au}_{6} \cdots \mathrm{PhF}$ complex. One can see that the HS and WH pictures both contribute to the substituent effects on the $\sigma \cdots \pi$ interactions in the $\mathrm{Au}_{6} \cdots \mathrm{PhX}$ complexes. The influence of electron-donating or -withdrawing substituent on the $\sigma \cdots \pi$ interaction can not be explained by a simple $\pi$-polarization model because the interaction strength and region varied with different substituent. The WH picture is very pronounced in the complexes with electron-withdrawing substituent. The results of IRI analysis shows that the substituent effects in the $\mathrm{Au}_{6} \cdots \mathrm{PhX}$ complexes is different from those in the $\mathrm{Bz} \cdots \mathrm{PhX}$ complexes.

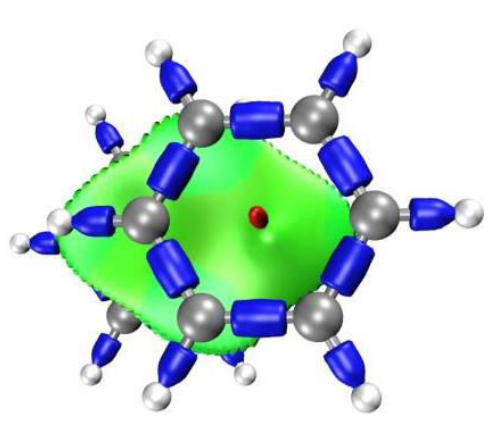

benzene dimer

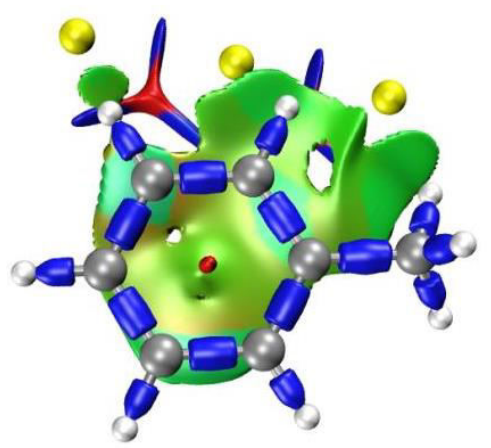

$\mathrm{Au}_{6} \cdots \mathrm{PhCH}_{3}$

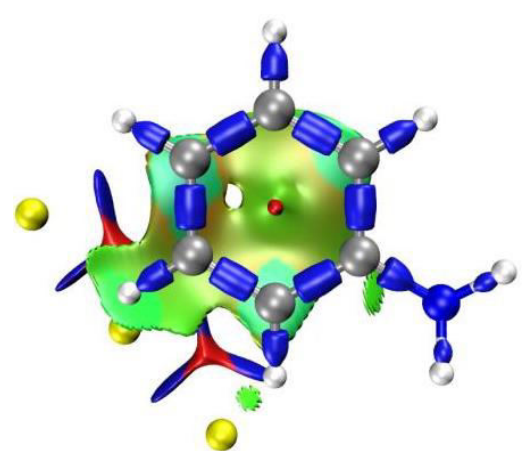

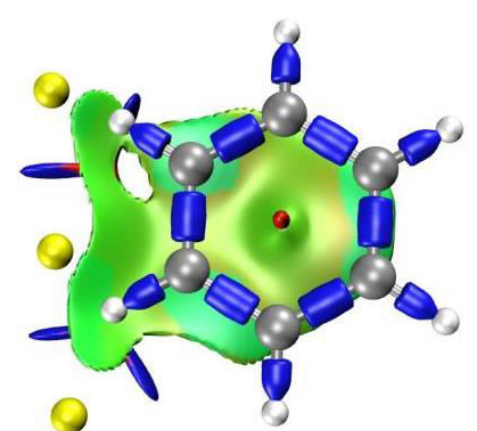

$\mathrm{Au}_{6} \cdots \mathrm{Bz}$

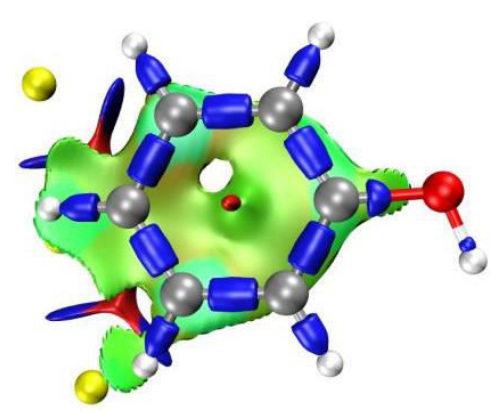

$\mathrm{Au}_{6} \cdots \mathrm{PhOH}$

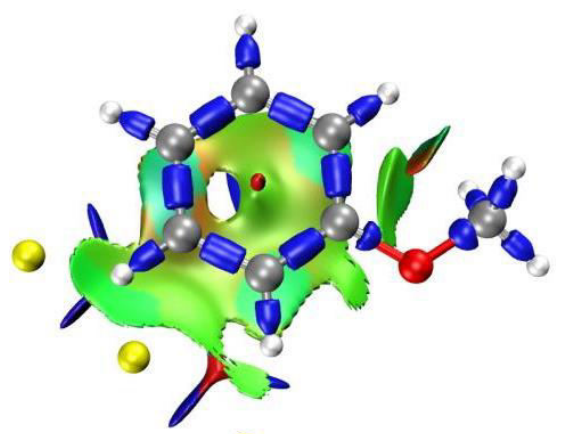

0 
$\mathrm{Au}_{6} \cdots \mathrm{PhNH}_{2}$

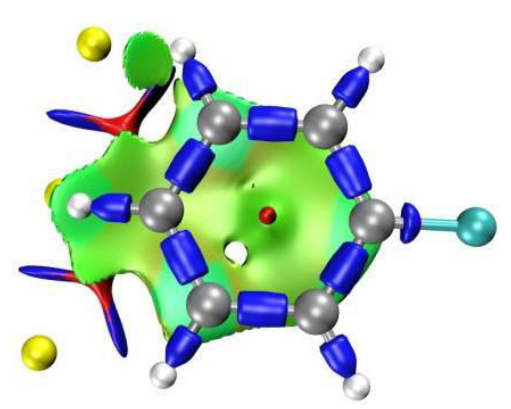

$\mathrm{Au}_{6} \cdots \mathrm{PhF}$

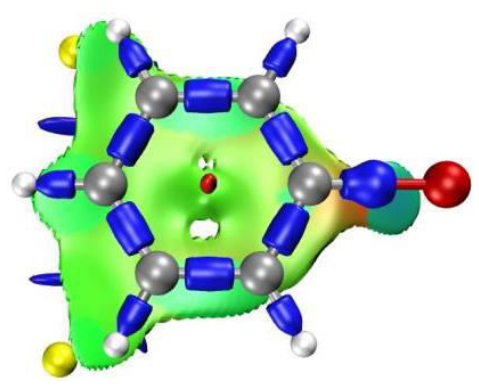

$\mathrm{Au}_{6} \cdots \mathrm{PhBr}$
$\mathrm{Au}_{6} \cdots \mathrm{PhOCH}_{3}$

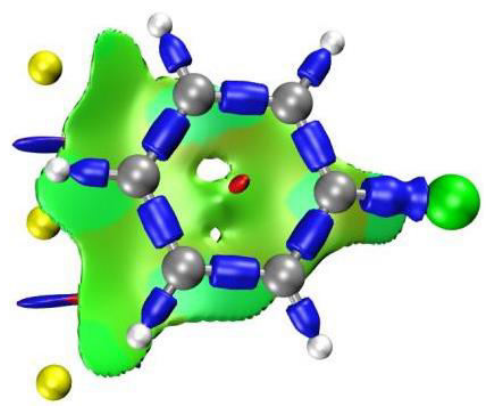

$\mathrm{Au}_{6} \cdots \mathrm{PhCl}$

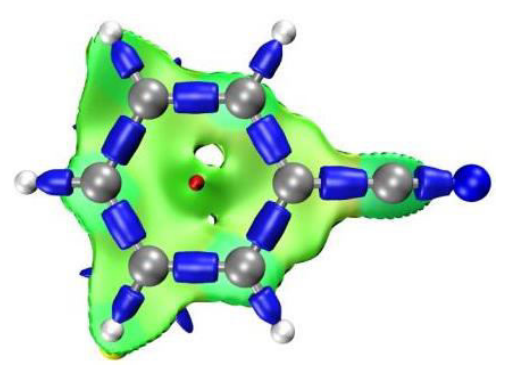

$\mathrm{Au}_{6} \cdot \mathrm{PhCN}$

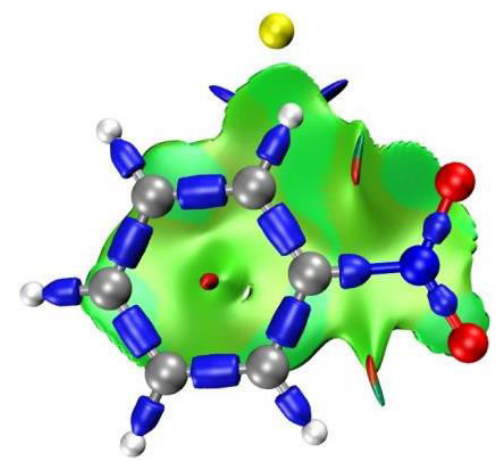

$\mathrm{Au}_{6} \cdots \mathrm{PhNO}_{2}$

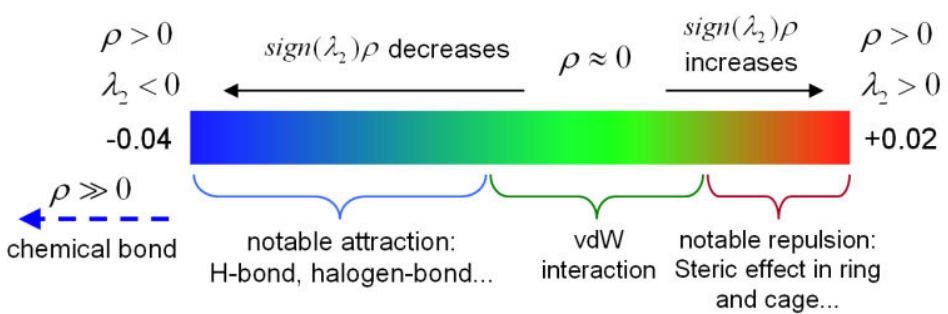

Figure 5 Isosurface maps of IRI=1.0 for the $\mathrm{Bz} \cdots \mathrm{BZ}, \mathrm{Au}_{6} \cdots \mathrm{BZ}$ and $\mathrm{Au}_{6} \cdots \mathrm{PhX}$ complexes. $\operatorname{sign}\left(\lambda_{2}\right) \rho$ is mapped on the isosurfaces according to coloring method illustrated in the figure.

\section{SAPT analysis}

The inherent nature of the $\sigma \cdots \pi$ interactions between $\mathrm{Au}_{6}$ cluster and substituted benzene can be understood using the SAPT approach. The SAPT energy can be 
expressed as $E_{S A P T}=E_{\text {elst }}+E_{\text {exch }}+E_{\text {ind }}+E_{\text {dis }}$. The $E_{\text {elst }}, E_{\text {ind }}$ and $E_{\text {dis }}$ terms reflect the electrostatic interaction, induction and dispersion contribution, respectively. The values of three terms are negative, and they are attractive forces when the complexes formed. The $E_{\text {exch }}$ term is the exchange-repulsion contribution with positive value, which behaves as a repulsive force. The energy components from SAPT calculations are extracted and plotted in Figure 6. As can be seen, dispersion dominates the $\sigma \cdots \pi$ interactions in the $\mathrm{Au}_{6} \cdots \mathrm{Bz}$ and $\mathrm{Au}_{6} \cdots \mathrm{PhX}$ complexes. This is consistent with the $\pi \cdots \pi$ interaction in the PD and PS benzene dimer. The electrostatic interaction is also important, which accounts for more than half of the dispersion term. The induction contribution, which is only $-1 \sim-3 \mathrm{kcal} \cdot \mathrm{mol}^{-1}$, is very weak relative to electrostatic interaction and dispersion contribution.

The electrostatic interaction in the $\mathrm{Au}_{6} \cdots \mathrm{Bz}$ complex is $-13.12 \mathrm{kcal} \cdot \mathrm{mol}^{-1}$, which is less negative than that of the complexes with $-\mathrm{CH}_{3},-\mathrm{OCH}_{3},-\mathrm{NH}_{2}$, and $-\mathrm{Br}$ substituent. This is very interesting because the electron-donating substituent can increase the $\pi$ density in the ring and decrease the acidic of hydrogen atom. It is worth noting that the exchange-repulsion contribution in the corresponding complexes becomes more positive compared to $\mathrm{Au}_{6} \cdots \mathrm{Bz}$. In a sense, $-\mathrm{Br}$ behaves like an electron-donating substituent in the $\mathrm{Au}_{6} \cdots \mathrm{PhBr}$ complex. In the $\mathrm{Au}_{6} \cdots \mathrm{PhOH}$ complex, the electrostatic interaction is less strong and the $E_{\text {exch }}$ term is smaller than those of $\mathrm{Au}_{6} \cdots \mathrm{Bz}$, which indicates that the $-\mathrm{OH}$ can be deemed as an electron-withdrawing substituent. The dispersion contribution increases in the $\mathrm{Au}_{6} \cdots \mathrm{PhX}$ complexes except for the $\mathrm{Au}_{6} \cdots \mathrm{PhF}$ complex. For the $\mathrm{Au}_{6} \cdots \mathrm{PhCH}_{3}, \mathrm{Au}_{6} \cdots \mathrm{PhNH}_{2}, \mathrm{Au}_{6} \cdots \mathrm{PhOCH}_{3}, \mathrm{Au}_{6} \cdots \mathrm{PhBr}$, and $\mathrm{Au}_{6} \cdots \mathrm{PhNO}_{2}$ complexes, the $E_{d i s}$ term spans in a range from -20.73 to $-25.28 \mathrm{kcal} \cdot \mathrm{mol}^{-1}$, which becomes more negative relative to $\mathrm{Au}_{6} \cdots \mathrm{Bz}$. This can attributed to the larger number of atoms and electrons in the substitute. Moreover, increment of the interaction region in the $\mathrm{Au}_{6} \cdots \mathrm{PhBr}$ and $\mathrm{Au}_{6} \cdots \mathrm{PhNO}_{2}$ complexes also play important role. 


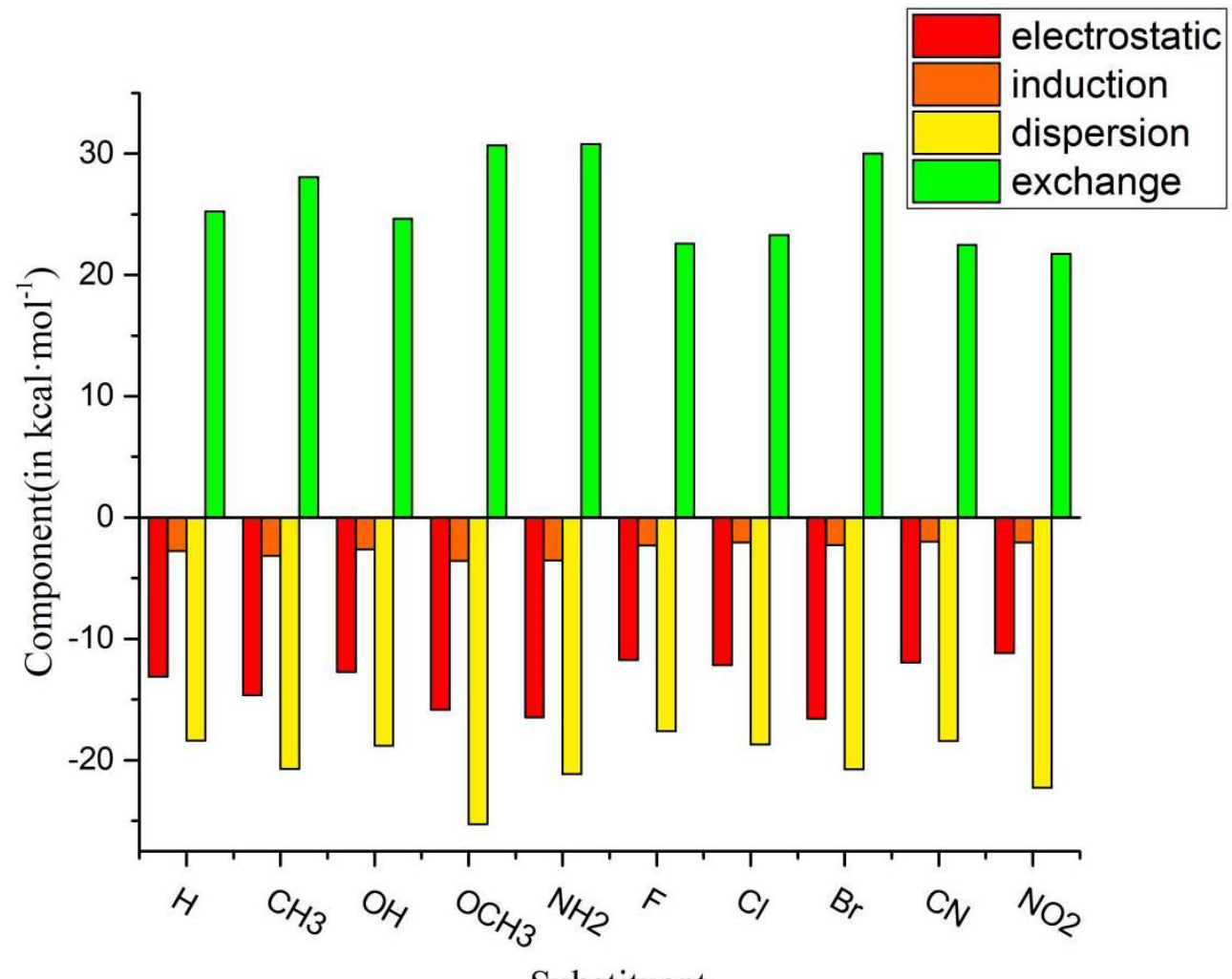

Figure 6 Components of SAPT energy between $\mathrm{Au}_{6}$ cluster and $\mathrm{PhX}\left(\mathrm{X}=\mathrm{H}, \mathrm{CH}_{3}, \mathrm{OH}, \mathrm{OCH}_{3}\right.$, $\left.\mathrm{NH}_{2}, \mathrm{~F}, \mathrm{Cl}, \mathrm{Br}, \mathrm{CN}, \mathrm{NO}_{2}\right)$.

\section{Conclusion}

The substituent effects on the $\sigma \cdots \pi$ interactions between $\mathrm{Au}_{6}$ cluster and substituted benzene have been explored using quantum chemical methods. The $\sigma \cdots \pi$ interaction in the $\mathrm{Au}_{6} \cdots \mathrm{Bz}$ complex is more strengthened than the $\pi \cdots \pi$ interaction of benzene dimer. Investigation on the $\mathrm{Au}_{6} \cdots \mathrm{PhX}\left(\mathrm{X}=\mathrm{CH}_{3}, \mathrm{OH}, \mathrm{OCH}_{3}, \mathrm{NH}_{2}, \mathrm{~F}, \mathrm{Cl}, \mathrm{Br}, \mathrm{CN}, \mathrm{NO}_{2}\right)$ complexes reveals that influence of electron-withdrawing substituent on the $\sigma^{\cdots} \pi$ interactions is more pronounced than the electron-donating substituent. Substituent -F have little influence on the binding strength of $\sigma \cdots \pi$ interactions, which is different from the substituent effect in the benzene dimer. IRI analysis indicates that the substituent effects usually associated with the variation of vdW interaction strength region. The interaction between the substituent and the aromatic ring is more prominent for the electron-withdrawing substituent than the electron-donating substituent. SAPT calculation suggests that dispersion dominates the $\sigma \cdots \pi$ interaction 
and electrostatic interaction has very important contribution. Substituent effect on the components of SAPT energy did not depend on the characteristic of the substituent. This study can enrich the knowledge of noncovalent interaction related to coinage metals, and also provide a different way to investigate the absorption of organic molecules on metal surfaces.

\section{Acknowledgments}

The author is grateful for the help from High Performance Computing Center in Shandong University and to Prof. Feng in Shandong University for the reasonable advice.

\section{References}

1. Martinez CR, Iverson BL (2012) Chem Sci 3:2191-2201

2. Riley KE, Hobza, P (2013) Acc Chem Res 46:927-936

3. Molčanov K, Kojić-Prodić B (2019) IUCrJ 6:156-166

4. Neel AJ, Hilton MJ, Sigman MS, Toste FD (2017) Nature 543:637-646

5. Steed JW, Atwood JL (2009) Supramolecular Chemistry, 2nd ed J Wiley \& sons

6. Tiekink RT, Zukerman-Schpector J, Eds. (2012) The Importance of $\pi$-Interactions in Crystal Engineering, Wiley

7. Salonen LM, Ellermann M, Diederich F (2011) Angew Chem Int Ed 50:4808-4842

8. Makwana KM, Mahalakshmi R (2015) Protein Sci 24:1920-1933

9. Mak CH (2016) J Phys Chem B 120:6010-6020

10. Hobza P, Selzle HL, Schlag EW (1994) J Am Chem Soc 116:3500-3506

11. Tsuzuki S, Honda K, Uchimaru T, Mikami M, Tanabe K (2002) J Am Chem Soc $124: 104-112$

12. Hill JG, Platts JA, Werner HJ (2006) Phys Chem Chem Phys 8:4072-4078

13. Sinnokrot MO, Sherrill CD (2006) J Phys Chem A 110:10656-10668

14. Grimme S (2003) J Chem Phys 118:9095-9102

15. Grimme S (2008) Angew Chem Int Ed 47:3430-3434

16. Bloom JWG, Wheeler SE (2011) Angew Chem Int Ed 50:7847-7849 
17. Hunter CA, Sanders JKM (1990) J Am Chem Soc 112:5525-5534

18. Sinnokrot MO, Sherrill CD (2004) J Am Chem Soc 126:7690-7697

19. Lee EC, Kim D, Jurecka P, Tarakeshwar P, Hobza P, Kim KS (2007) J Phys Chem A $111: 3446-3457$

20. Wheeler SE, Houk KN (2008) J Am Chem Soc 130:10854-10855

21. Arnstein SA, Sherrill CD (2008) Phys Chem Chem Phys 10:2646-2655

22. Ringer AL, Sherrill CD (2009) J Am Chem Soc 131:4574-4575

23. Wheeler SE (2011) J Am Chem Soc 133:10262-10274

24. Hohenstein EG, Duan J, Sherrill CD (2011) J Am Chem Soc 133:13244-13247

25. Raju RK, Bloom JWG, Wheeler SE (2013) J Chem Theory Comput 9:3479-3490

26. Parrish RM, Sherrill CD (2014) J Am Chem Soc 136:17386-17389

27. Hunter CA, Low CMR, Vinter JG, Zonta C (2003) J Am Chem Soc 125:9936-9937

28. Cockroft SL, Hunter CA, Lawson KR, Perkins J, Urch CJ (2005) J Am Chem Soc $127: 8594-8595$

29. Stenlid JH, Johansson AJ, Brinck T (2018). Phys Chem Chem Phys 20:2676-2692

30. Stenlid JH, Brinck T (2017). J Am Chem Soc 139:11012-11015

31. Frontera A, Bauzá A (2018). Chem Eur J 24:7228-7234

32. Piña M, Frontera A, Bauzá A (2020). J Phys Chem Lett 11:8259-8263

33. Ulloa CO, Ponce-Vargas M, Muñoz-Castro A (2018). J Phys Chem C $122: 25110-25117$

34. Bauzá A, Frontera A (2018). Inorganics 6:64-74

35. Reina M, Martinez A (2018). Comput Theor Chem 1130:15-23

36. Zierkiewicz W, Michalczyk M, Scheiner S (2018). Phys Chem Chem Phys 20:22498-22509

37. Clark T, Hennemann M, Murray JS, Politzer P (2007). J Mol Model 13:291-296

38. Vanin M, Mortensen JJ, Kelkkanen AK, Garcia-Lastra JM, Thygesen KS, Jacobsen KW (2010) Phys Rev B 81:081408-081411

39. Toyoda K, Hamada I, Lee K, Yanagisawa S, Morikawa Y (2010) J Chem Phys $132: 134703-134711$ 
40. Wellendorff J, Kelkkanen A, Mortensen JJ, Lundqvist BI, Bligaard T (2010) Top Catal 53:378-383

41. Abad E, Dappe YJ, Martínez JI, Flores F, Ortega J (2011) J Chem Phys 134:044701-044708

42. Yildirim H, Greber T, Kara A (2013) J Phys Chem C 117:20572-20583

43. Peköz R, Johnston K, Donadio D (2014) 118:6235-6241

44. Miller DP, Simpson S, Tymińska N, Zurek E (2015) J Chem Phys $142: 101924-101936$

45. Gruene P, Butschke B, Lyon JT, Rayner DM, Fielicke A (2014). Z Phys Chem $228: 337-350$

46. Baek H,Moon J, Kim J (2017). J Phys Chem A 121:2410-2419

47. Perdew JP, Burke K, Ernzerhof M (1997) Phys Rev Lett 78:1396

48. Adamo C, Barone V (1999) J Chem Phys 110:6158-69

49. Weigend F, Ahlrichs R (2005) Phys Chem Chem Phys 7:3297-3305

50. Zhao Y, Truhlar DG (2006). J Chem Phys 125:194101-194118

51. Quintal MM, Karton A, Iron MA, Boese AD, Martin JML (2006). J Phys Chem A $110: 709-716$

52. Lousada CM, Johansson AJ, Brinck T, Jonsson M (2013) Phys Chem Chem Phys $15: 5539-5552$

53. Grimme S, Antony J, Ehrlich S, Krieg H (2010). J Chem Phys $132: 154104-154119$

54. Frisch MJ, Trucks GW, Schlegel HB, Scuseria GE, Robb MA, Cheeseman JR, Scalmani G, Barone V, Mennucci B, Petersson GA, Nakatsuji H, Caricato M, Li X, Hratchian HP, Izmaylov AF, Bloino J, Zheng G, Sonnenberg JL, Hada M, Ehara M, Toyota K, Fukuda R, Hasegawa J, Ishida M, Nakajima T, Honda Y, Kitao O, Nakai H, Vreven T, Montgomery JA Jr, Peralta JE, Ogliaro F, Bearpark M, Heyd JJ, Brothers E, Kudin KN, Staroverov VN, Kobayashi R, Normand J, Raghavachari K, Rendell A, Burant JC, Iyengar SS, Tomasi J, Cossi M, Rega N, Millam JM, Klene M, Knox JE, Cross JB, Bakken V, Adamo C, Jaramillo J, Gomperts R, Stratmann RE, Yazyev O, Austin AJ, Cammi R, Pomelli C, Ochterski JW, Martin RL, Morokuma K, Zakrzewski 
VG, Voth GA, Salvador P, Dannenberg JJ, Dapprich S, Daniels AD, Farkas O,

Foresman JB, Ortiz JV, Cioslowski J, Fox DJ (2013). Gaussian 09, Revision D.01.

Gaussian Inc., Wallingford

55. Grimme S, Steinmetz M (2016) Phys Chem Chem Phys 18:20926-20937

56. Boys SF, Bernardi F (1970). Mol Phys 19:553-566

57. Neese F (2018) WIREs Comput Mol Sci 8:1327-1332

58. Kossmann S, Neese F (2009) Chem Phys Lett 481:240-243

59. Hohenstein EG, Sherrill CD (2012). WIREs: Comp Mol Sci 2:304-326

60. Parrish RM, Burns LA, Smith DGA, Simmonett AC, DePrince AE, Hohenstein

EG, Bozkaya U, Sokolov AY, Di Remigio R, Richard RM, Gonthier JF, James AM,

McAlexander HR, Kumar A, Saitow M, Wang X, Pritchard BP, Verma P, Schaefer HF,

Patkowski K, King RA, Valeev EF, Evangelista FA, Turney JM, Crawford TD, Sherrill CD (2017). J Chem Theory Comput 13:3185-3197

61. Lu T, Chen QX (2021) Chemistry-Methods 1:231-239

62. Lu T, Chen FW (2012) J Comp Chem 33:580-592

63. Humphrey W, Dalke A, Schulten K (1996) J Molec Graphics 14:33-38

64. Řezáč J, Riley KE, Hobza P (2011) J Chem Theory Comput 7:2427-2438

65. Syomin D, Kim J, Koel BE, Ellison GB (2001) J Phys Chem B 105:8387-8394 